\title{
ARISTÓTELES E A NOÇÃO DE SUJEITO DE PREDICAÇÃO (SE- GUNDOS ANALÍTICOS I 22, 83A 1-14)
}

Lucas Angioni (Unicamp)

Angioni.lucas@gmail.com

Resumo: Meu objetivo neste artigo consiste em explorar alguns aspectos da noção de sujeito de predicação em Aristóteles. Mais precisamente, pretendo examinar o argumento que Aristóteles desenvolve em Segundos Analíticos I 22, 83a 1-14, no qual podemos encontrar alguns dos requisitos pelos quais Aristóteles delimita a noção de sujeito de predicação. Pretendo mostrar de que modo a noção de sujeito proposta por Aristóteles nesse argumento é bem distinta da noção de sujeito proposta no tratado das Categorias, embora ambas as noções estejam longe de ser incompativeis entre si. Finalizarei o artigo com algumas considerações filológicas que, entre outras coisas, elucidam minhas razões para a tradução de "hypokeimenon" como "sujeito" ou como "algo subjacente".

Palavras-chave: Ontologia, Semântica, Predicação, Essencialismo, Substância, Categorias.

I.

Em Segundos Analíticos I 22, Aristóteles pretende mostrar que não é possível estender séries predicativas indefinidamente (ad inifinitum), seja "para cima" (tomando como sujeito de uma nova predicação aquilo que era predicado na sentença anterior), seja "para baixo" (tomando o sujeito da sentença anterior 
como predicado que se atribui a um novo sujeito). Não pretendo investigar a fundo as razões pelas quais Aristóteles está interessado nessa prova no contexto em questão, que trata da noção de demonstração científica. Meu escopo recai tão apenas no modo pelo qual Aristóteles analisa as predicações, para provar que é impossível estender séries predicativas ao infinito. Meu objetivo, mais precisamente, consiste em mostrar que o "hypokeimenon" de uma predicação (ao menos do tipo de predicação que está em pauta no argumento) não é nem a "substância primeira" isoladamente tomada (previamente à sua relação com uma substância segunda), nem a "substância segunda" sem remissão às substâncias primeiras, mas a devida combinação de ambas. Será impossível separar desse objetivo conceitual um escopo de natureza mais estritamente filológica, mas que tem muitas conseqüências sobre a interpretação da metafísica e da lógica de Aristóteles, a saber: mostrar que as expressões "ser afirmado de um sujeito" e "não ser afirmado de um sujeito" não podem ser tomadas no sentido mais tradicional, fundado em certa interpretação das Categorias².

É preciso deixar claro, no entanto, que o argumento que Aristóteles desenvolve em Segundos Analíticos 83a 1-14 restringe-se ao campo das predicações heterogêneas ou, em outra terminologia, ao campo das predicações não-definicionais. Em 82b 37-83a 1, Aristóteles ofereceu breve argumento em favor da tese de que não é possível estender ao infinito séries de predicações definicionais. Em 83a 1-14, ele toma, em contrapartida, as predicações nas quais o predicado não pretende definir o sujeito, mas pretende atribuir-lhe alguma propriedade que não estava pressuposta em sua mera definição. Chamo as predicações desse tipo de heterogêneas. Devo ressaltar que, neste meu texto, quando falo de predicações, estou sempre a pressu- 
por que se trata de predicações heterogêneas, a não ser que haja alguma indicação em contrário ${ }^{3}$.

\section{II.}

Comecemos, então, a acompanhar o argumento que Aristóteles propõe em Segundos Analíticos I 22, 83a 1-14. No intuito de provar que predicações não podem ser estendidas ao infinito, Aristóteles propõe duas sentenças (83a, p.. 1-3):

(1) "um branco caminha";

(2) "aquilo grande é lenho".

A primeira sentença é introduzida como possível caso em que se estende a predicação "para cima": "branco", que usualmente se atribui como predicado a um sujeito qualquer, é tomado como sujeito ao qual se atribui um novo predicado, "caminha”. Já a segunda sentença é introduzida como possível caso em que se estende a predicação "para baixo": lenho, que usualmente é tomado como sujeito a que se atribui um predicado qualquer (branco, por exemplo) é tomado como predicado de um sujeito.

Aristóteles parece pressupor o fato que, na língua ordinária, tais sentenças são usadas de modo eficaz e, além do mais, são verdadeiras. Supõe-se que os interlocutores que usam tais sentenças se entendem entre si quanto aos pressupostos implícitos que lhes asseguram uma referência precisa a fatos reconhecidos. Embora tais sentenças sejam verdadeiras e tenham eficácia pragmática, elas não podem ser usadas como prova de que uma série predicativa poderia ser estendida ao infinito. Aristóteles as admite como verdadeiras e eficazes no plano da linguagem comum, mas ele não pode admiti-las como formulações satisfatórias, sob o ponto de vista da questão em pauta. Aristóteles se esforçará para provar que, em tais sentenças, o sujeito gramatical que consta nas formulações originais não é, 
do ponto de vista semântico, um autêntico sujeito: ele não introduz de modo apropriado o objeto do qual se está realmente a falar.

Assim, a sentença (1) apenas aparentemente teria introduzido um novo sujeito de predicação "para cima", ao passo que a sentença (2) apenas aparentemente teria introduzido um novo sujeito de predicação "para baixo". Ambas as sentenças não respeitam certos critérios que Aristóteles reconhece para a correta ordem dos termos de uma predicação. Na seqüência do argumento, Aristóteles propõe (em quiasmo) sentenças que restabeleceriam a boa ordem ${ }^{4}$ dos termos na predicação e, assim, dissipariam a aparência de que teríamos estendido a predicação com "novos sujeitos", para cima ou para baixo. As sentenças que ele introduz são as seguintes:

(2') "um lenho é grande", que restabelece a ordem correta dos termos, a qual havia sido desconsiderada em (2). Assim, quando se diz "aquilo grande é lenho", o que se quer dizer é que aquele lenho é grande.

(1') "um homem caminha", que explicita o sujeito subentendido na sentença (1), ou seja, explicita que o "branco", na sentença (1), remete a um homem branco.

As novas sentenças introduzidas por Aristóteles restabelecem a boa ordem dos termos e explicitam pressupostos que estavam implícitos nas sentenças iniciais, mas o próprio Aristóteles nota a necessidade de analisar com mais detalhe a trama semântica nelas envolvida. Em vez de voltar aos exemplos anteriores, Aristóteles introduz outra sentença, "o branco é lenho", a qual, para a análise requisitada no contexto, tem o mesmo efeito que a sentença "aquele grande é lenho". O interesse de Aristóteles é analisar um tipo de sentença em que a ordem natural entre sujeito e predicado esteja simplesmente invertida. Assim, o ponto de Aristóteles é o seguinte: quando se 
afirma "o branco é lenho", não se pretende dizer que o "branco" seja o subjacente para o predicado "lenho". Ou seja, apesar de "branco" desempenhar a função de sujeito gramatical da sentença, "branco" não é o subjacente ao qual seria atribuída a propriedade de ser um lenho. Quando se afirma "o branco é lenho", pretende-se afirmar que aquilo que é designado como "branco" é certa coisa identificada pela propriedade de ser um lenho.

$\mathrm{Na}$ frase explicativa que se segue (83a 7-9), Aristóteles afirma que essa coisa, já restabelecida na função de sujeito da predicação, tornou-se (egeneto) lenho sem ser branco ou sem ser precisamente algo branco. O uso do verbo "tornar-se" (gignesthai), nesse contexto, não tem absolutamente nenhuma conexão com a noção de devir. Trata-se de uso comum do verbo: "vir a ser $x$ " significa "desempenhar a função que é própria de $x$ " ou "assumir o lugar ou o papel de $x^{\text {" }}$. Aristóteles quer dizer algo bem simples: a coisa que "veio a ser" designada como lenho é assim designada sem que, para tal designação, lhe fosse necessário ter a propriedade de ser branca. Em outras palavras: para designar uma dada coisa como "lenho", não é condição necessária identificar essa mesma coisa sob a propriedade de ser branca ou de ser precisamente algo branco.

Aristóteles, no entanto, não quer dizer apenas que, para algo ser um lenho, não é necessário que ele seja branco. O que Aristóteles quer dizer pode ser mais bem compreendido pela análise da sentença seguinte: "o lenho é branco" (cf. 83a 9-10), que é simplesmente a forma corrigida da sentença anterior, "o branco é lenho". Ao examinar a sentença "o lenho é branco", Aristóteles tomará como contraste outra sentença, "o musical é branco" (cf. 83a 10-12). Nesta última sentença, não temos exatamente uma inversão na ordem natural dos termos. $\mathrm{O}$ que ocorre é que um termo que usualmente é atribuído como pre- 
dicado ("musical") aparece na posição de sujeito de predicação ulterior. O que Aristóteles diz sobre o contraste entre essas duas sentenças, "o lenho é branco" e "o musical é branco", elucida de que modo um termo é apto a desempenhar a função de sujeito em uma predicação.

Aristóteles argumenta que, quando usamos a sentença "o lenho é branco", não afirmamos que é branco (ou seja, que é autêntico sujeito a que se atribui o predicado branco) uma outra coisa, a que lenho fosse atribuído como predicado acidental. É preciso cautela para compreender o sentido do argumento. Qual é o escopo da negação "não", que pus em itálico, e que corresponde ao advérbio de negação "ouk" que aparece em 83a 9 ? O texto que sucede a negação, ao que parece, consiste de duas partes: (i) afirmamos que é outro item $x$ que é branco ${ }^{6}$, (ii) atribuímos a esse outro item $x$ a propriedade de ser lenho. Suponha-se que o argumento de Aristóteles consista, então, em dizer que, ao usar a sentença "o lenho é branco", não queremos dizer (nem mesmo implicitamente) nem o que se descreve em (i), nem o que se descreve em (ii) ${ }^{7}$. Assim, ao afirmar que o lenho é branco:

(i) não afirmamos que é outro item $x$ (diferente do lenho) que é branco;

(ii) não atribuímos a esse outro item $x$ a propriedade de ser lenho.

Entendido desse modo, o argumento de Aristóteles resultaria na tese que a sentença "o lenho é branco" não poderia de modo algum ser entendida como equivalente à sentença "existe um $x$ tal que $x$ é lenho e $x$ é branco".

No entanto, creio que Aristóteles quer dizer algo bem diferente. Em 83a 10, na expressão grega para nossa cláusula (ii), a conexão entre " $x$ " (ekeinôi) e "lenho" se estabelece pelo verbo "sumbebeke", o qual, longe de introduzir tão somente a noção 
pura de "atribuir um predicado a um sujeito", consiste, neste contexto como também em outros, em jargão mais preciso, pelo qual Aristóteles introduz a noção de atribuição heterogênea, isto é, o tipo de atribuição na qual o predicado não está incluído na definição do sujeito a que se atribui. Assim, aquilo que há pouco designei como "cláusula (ii)" introduz algo bem específico: a noção de que a propriedade de ser lenho é atribuída a $x$ como propriedade acidental de $x$. A cláusula (ii), portanto, poderia ser substituída por uma cláusula retificada (ii'), mas julgamos vantajoso preservá-la, na análise subseqüente, e introduzir uma terceira cláusula:

(iii) atribuímos a esse outro item $x$ a propriedade de ser lenho a título de propriedade acidental de $x$.

Esclarecido o sentido exato da segunda cláusula, podemos voltar ao problema do escopo da negação introduzida no argumento de Aristóteles em 83a 9. O texto que sucede a negação consiste, pois, de três partes: (i) afirmamos que é outro item $x$ (diferente do lenho) que é branco, (ii) atribuímos a esse outro item $x$ a propriedade de ser lenho; (iii) atribuímos a esse outro item $x$ a propriedade de ser lenho a título de propriedade acidental de $x$. O desemaranhamento do texto em três cláusulas facilita-me a exposição subseqüente. Do ponto de vista abstrato da gramática, pode-se dizer que a negação "não" está apenas com o passo (i), ou está com os passos (i)-(ii)-(iii) tomados conjuntamente ${ }^{8}$. $\mathrm{O}$ contexto do argumento sugere, porém, que a negação nega conjuntamente, do ponto de vista gramatical, os passos (i)-(ii)-(iii). No entanto, sabemos que, para que seja verdadeira a negação de uma conjunção, basta que seja falso um dos conjuntivos. Assim, o sentido do argumento de Aristóteles poderia ser interpretado de acordo com uma das duas seguintes opções ${ }^{9}$ : 
Opção "ortodoxa”: quando usamos a sentença “o lenho é branco":

(i) não afirmamos que é outro item, $x$ (diferente do lenho), que é branco;

(ii) não atribuímos a esse outro item $x$ a propriedade de ser lenho;

(iii) não atribuímos a esse outro item $x$ a propriedade de ser lenho a título de propriedade acidental de $x$.

Como alternativa, proponho a seguinte opção: Aristóteles quer dizer que, quando usamos a sentença "o lenho é branco":

(i) afirmamos que outro item, $x$ (diferente do lenho), é que é branco;

(ii) atribuímos a esse outro item $x$ a propriedade de ser lenho;

(iii) não atribuímos a esse outro item $x$ a propriedade de ser lenho a título de propriedade acidental de $x$.

De acordo com minha interpretação, seria admissível reescrever a sentença "o lenho é branco" como "existe um $x$ tal que $x$ é lenho e $x$ é branco". Não estou a sugerir que Aristóteles antecipou o conceito de "quantificação existencial"; apenas afirmo que interpretar a sentença "o lenho é branco" nesses termos não é um escândalo ${ }^{10}$. No entanto, para captar o que a sentença quer dizer, bem como para captar qual é a função que ela desempenha no argumento encarregado de especificar critérios mais estritos para conceber a noção de sujeito de predicação, essa análise é apenas parcialmente correta, pois deixa escapar um ponto que, para Aristóteles, é o mais relevante. Podemos dizer que a sentença original "o lenho é branco" envolve, como sentenças elementares de que se constitui, " $x$ é lenho" e " $x$ é branco". No entanto, o ponto mais importante no argumento de Aristóteles consiste em ressaltar que, na primeira dessas sentenças elementares, “x é lenho”, lenho não é um 
predicado acidental. Seu ponto principal, como tentarei explicitar, é o seguinte: lenho, não sendo um predicado acidental de coisa alguma, não precisa ser atribuído a "outra coisa", e essa noção de "outra coisa" (heteron ti) também é um jargão, com sentido bem preciso.

Meu ponto poderá ser mais bem entendido por contraste com a outra sentença envolvida no argumento de Aristóteles: “o musical é branco". Também esta sentença é suscetível à mesma análise, ou seja: tal sentença envolve duas mais elementares, " $x$ é musical" e " $x$ é branco", e pode ser entendida como equivalente a "existe um $x$ tal que $x$ é musical e $x$ é branco". No entanto, na medida em que musical é um acidente (ou melhor, é algo incluído na categoria dos acidentes), ele precisa, ainda, ser dito de outra coisa. No exemplo de Aristóteles, essa outra coisa é um ser humano (cf. 83a, p. 11-12), de modo que não seria incorreto dizer que a análise da sentença inicial envolveria três predicados mais elementares, relativos a um mesmo sujeito: "existe um $x$ tal que $x$ é homem, $x$ é musical e $x$ é branco".

Eis o contraste relevante: aquilo que Aristóteles dissera não ser requisitado no caso de "o lenho é branco" torna-se agora requisitado para a sentença "o musical é branco", a saber: tratar o sujeito da sentença original como algo que se afirma de outra coisa. Assim, Aristóteles diz que, na sentença "o musical é branco", afirma-se que é branco (ou seja, que é autêntico sujeito a que se atribui o predicado branco) justamente uma outra coisa, a saber, ser humano, ao qual se atribui o predicado acidental musical, que figurava como sujeito na formulação original da sentença. Para fins de simetria da exposição, seja-me permitido usar novamente as três cláusulas que há pouco introduzi. Teríamos o seguinte: quando dizemos que "o musical é branco": 
(i) afirmamos que outro item, $x$ (diferente do musical), é que é branco;

(ii) atribuímos a esse outro item $x$ a propriedade de ser musical;

(iii) atribuímos a esse outro item $x$ a propriedade de ser musical a título de propriedade acidental de $x$.

Essa situação se depreende de 83a 10-11, antes do trecho entre parênteses. No texto colocado entre parênteses pelos editores, isto é, em 83a 11-12, Aristóteles esclarece que, ao usar a sentença "o musical é branco" (em um dado contexto, obviamente), queremos dizer que um ser humano é que é musical e branco. É fácil inferir, por comparação com diversos textos relevantes ${ }^{11}$, que o termo "ser humano" encontra-se na mesma situação que se aplica ao "lenho", de tal modo que se pode concluir o seguinte: o uso da sentença "o musical é branco" para se referir a um ser humano pode ser analisado pelas seguintes condições:

(i) afirmamos que outro item, $x$ (diferente de musical, que é o sujeito gramatical da formulação original), é que é branco;

(ii) atribuímos a esse outro item $x$ a propriedade de ser musical;

(iii) atribuímos a esse outro item $x$ a propriedade de ser musical a título de propriedade acidental de $x$;

(iv) atribuímos a esse outro item $x$ a propriedade de ser um homem;

(v) não é a título de propriedade acidental que a propriedade de ser um homem é atribuída a $x$.

Isso se depreende pela continuação do argumento. Após o texto colocado entre parênteses pelos editores, Aristóteles retoma o caso da sentença "o lenho é branco" e reafirma que, em tal sentença, é o lenho que é o subjacente, ou seja, não é uma outra coisa (diferente de "lenho", que era o sujeito grama- 
tical da formulação original) que viria a exercer o papel de subjacente. Mais do que isso: Aristóteles afirma que o lenho assumiu a função de subjacente - ou seja, "tornou-se" subjacente, no contexto dessa sentença ${ }^{12}$ - sem ser uma outra coisa, a não ser aquilo que precisamente lenho ou um lenho é. Aristóteles quer dizer que um termo como "lenho" pode ser subjacente em uma predicação heterogênea somente se satisfizer conjuntamente as seguintes condições:

(i) lenho não precisa ser outra coisa, o que equivale a dizer (como elucidarei mais adiante) que ele não precisa ser afirmado de algo subjacente ${ }^{13}$;

(ii) basta que lenho seja aquilo que precisamente lenho é ou algum lenho é.

Esta segunda condição é bem precisa e sutil. Ao dizer "lenho ou algum lenho”, Aristóteles não está a propor duas alternativas que seriam igualmente satisfatórias. Longe disso: "ou", neste caso, introduz leve retificação e pode perfeitamente ser traduzido por "ou melhor". Assim, Aristóteles quer dizer o seguinte: aquilo que é subjacente do predicado "branco" na sentença "o lenho é branco" satisfaz dois requisitos, a saber, está identificado sob uma propriedade substancial (mas não acidental), qual seja, ser lenho, e consiste em uma instância individual dessa propriedade substancial, isto é, consiste em um lenho individual.

A tese que Aristóteles parece estabelecer é a seguinte: são indivíduos (como um dado lenho) que desempenham a função de subjacente em predicações não-definicionais, mas um indivíduo pode desempenhar tal função somente se estiver suficientemente identificado por uma propriedade essencial. Ora, a capacidade de identificar indivíduos de modo a transformá-los em subjacentes de predicações é que demarca a distinção entre a categoria da substância e as categorias de acidentes: as pro- 
priedades que efetuam essa identificação de modo suficiente são da categoria da substância; as que não são capazes de efetuar essa identificação são das categorias de acidentes. Pode-se concluir, assim, que a noção de "subjacente de uma predicação" é concebida de tal modo que não pode ser satisfeita nem por indivíduos tomados à parte de qualquer propriedade substancial, nem por propriedades substanciais tomadas sem nenhuma referência a um indivíduo. $\mathrm{O}$ resultado disso é que não se pode atribuir o título de "subjacente das predicações" nem aos indivíduos, tomados em si mesmos sem nenhuma consideração por propriedades essenciais, nem às propriedades essenciais em si mesmas, sem nenhuma referência a indivíduos. Para usar a nomenclatura das Categorias, pode-se dizer que o argumento de Aristóteles em Segundos Analíticos I 22 conclui que o título de "subjacente das predicações" (isto é, das predicações não-definicionais) não pode ser atribuído nem às "substâncias primeiras", isoladamente, nem às "substâncias segundas", isoladamente. E, de fato, o uso que Aristóteles faz do termo "hypokeimenon”, em várias obras, é coerente com essa conclusão: Aristóteles usa tal termo para se referir à categoria da substância, em contraste com as demais categorias, sem explicitar se se trata das substâncias primeiras ou das segundas ${ }^{14}$. Essa ausência de explicitação poderia ser tomada como falha na exposição ou mesmo na teoria, mas o fato é que Aristóteles nem precisa nem poderia tomar uma decisão entre "substâncias primeiras" ou "substâncias segundas". A categoria da substância é correlata à noção de subjacente (e é co-extensiva com ela) ${ }^{15}$, pois tal noção envolve a noção de propriedades essenciais referidas a indivíduos. 
III.

A teoria da predicação que resulta do argumento de Segundos Analíticos I 22 é, assim, perfeitamente compatível com os traços gerais da ontologia que se encontra no opúsculo $\mathrm{Ca}$ tegorias. Há, nas Categorias, um anti-platonismo radical: Aristóteles nega que as substâncias segundas possam existir em si mesmas, sem estar inerentes em indivíduos ${ }^{16}$. O mesmo ponto é resgatado por Aristóteles nos Segundos Analíticos, quando ele diz, cuidadosamente, ao introduzir os requisitos sob os quais o termo "lenho" é subjacente, que: "ou melhor, um dado lenho" $\left(83^{\mathrm{a}}\right.$, p. 14).

No entanto, há diferenças consideráveis entre as duas obras. Em Segundos Analíticos 83a 1-14, Aristóteles está mais interessado no contraste entre propriedades acidentais versus propriedades substanciais, que é o foco principal de seu argumento. Seria talvez plausível afirmar que, se há uma teoria da predicação nas Categorias, ela parece atribuir primazia antes às substâncias primeiras, em detrimento das segundas. Ao menos é certo dizer que Aristóteles jamais ressalta, nas Categorias, o papel absolutamente imprescindível das substâncias segundas na identificação de indivíduos. Mas não é preciso exagerar essas diferenças entre as duas obras. Não é pertinente sugerir que elas proporiam ou pressuporiam ontologias incompatíveis entre si, tampouco é pertinente supor que Aristóteles tenha mudado de opinião de uma obra para outra. Os interesses argumentativos em cada respectiva obra são distintos e, por isso, as ênfases são distintas.

Em todo caso, é conveniente ressaltar o seguinte ponto: nas Categorias, a noção de "hypokeimenon" está longe de ser compreendida tão somente no horizonte da predicação. Aristóteles parece mesclar a noção de substrato de inerência e a no- 
ção de sujeito de predicação $0^{17}$. Estou longe de sugerir que essa mescla seja sintoma de confusão. A rigor, nem sequer preciso discutir esse ponto. Meu interesse consiste em ressaltar outra coisa, a saber: nas Categorias, a noção de sujeito de predicação não é tratada com muita profundidade e Aristóteles parece contentar-se em delimitá-la mediante um critério que é meramente gramatical ${ }^{18}$. De fato, ao dizer que as substâncias segundas "são afirmadas de um sujeito" (1a 21-22, 2a 19-27), Aristóteles parece ter em mente algo muito simples: dado o esquema sentencial da predicação, "S é $P$ ", pode-se dizer que é sujeito qualquer termo que, nesse esquema, substitua "S", ou seja, qualquer termo que fique à esquerda do "é". Somente sob essa concepção minimalista de sujeito é que se pode compreender por que Aristóteles afirma que um predicado essencial como "homem" é afirmado de um sujeito, quando é afirmado de algum homem, como Sócrates, formando a sentença "Sócrates é homem" (cf. 1a 21-22, 2a 21-22). Em diversos textos ${ }^{19}$, no entanto, Aristóteles afirma (ou pressupõe) que predicados que introduzem propriedades essenciais não são afirmados de um sujeito, o que se poderia afigurar como flagrante contradição com o que se diz nas Categorias. Mas, a despeito das aparências, não há contradição alguma: a noção de "hypokeimenon" é diversa em cada respectivo contexto. Nas Categorias, "ser afirmado de um hypokeimenon" consiste simplesmente em ocupar o lugar de "P" em um esquema predicativo que satisfaz a forma "S é $P$ " ou alguma forma equivalente, como " $P$ afirma-se de $S$ "20. Já nos Segundos Analíticos e demais textos, "ser afirmado de um hypokeimenon" é uma noção bem mais complexa, que se delimita pela satisfação conjunta dos seguintes critérios: um predicado $P$ é afirmado de um hypokeimenon se e somente se:

(1) $P$ é atribuído a $S$ em um esquema predicativo que satifaz a forma "S é $P$ " (ou alguma forma equivalente); 
(2) $P$ não constitui, de modo algum, a essência de $S$, e, no mais das vezes, nem sequer introduz uma propriedade necessária de $S^{21}$.

Essa segunda exigência pode ser formulada de outro modo: o sujeito $S$, no contexto dessa predicação, está já configurado em sua essência, independentemente do predicado $P$, de modo que aquilo que $S$ é, em si mesmo, não consiste em ter a propriedade introduzida pelo predicado $P$, tampouco consiste em ter uma propriedade que fosse uma especificação homogênea da propriedade introduzida pelo predicado $P$.

Por outro lado, a noção de subjacente é definida por Aristóteles como "aquilo que não se afirma de um subjacente" (cf. Metafísica 1028b, p. 36-37). Obviamente, essa expressão deve ser entendida como negação da conjunção das duas exigências acima introduzidas. A negação de uma conjunção, no entanto, pode ser verdadeira quando apenas um dos itens conjuntivos é falso. Nesse sentido, a definição da noção de subjacente poderia ser entendida de dois modos. Algo é um subjacente se e somente se:

(1') não é atribuído a $S$ em um esquema predicativo que satisfaz a forma "S é $P$ " (ou alguma forma equivalente);

(2') constitui a essência do sujeito $S$ a que se atribui ${ }^{22}$.

Note-se que, nessa interpretação, a cláusula (2') torna-se desnecessária e inócua, dado que a primeira cláusula já exclui totalmente a possibilidade de o hypokeimenon ser atribuído a um sujeito qualquer. A outra interpretação seria a seguinte: algo é subjacente se e somente se:

(1") é atribuído a $S$ em um esquema predicativo que satisfaz a forma "S é $P$ " (ou alguma forma equivalente);

(2") constitui de modo algum a essência do sujeito $S$ a que se atribui. 
Ora, a interpretação que nos permite compreender Aristóteles de modo satisfatório, tanto do ponto de vista filosófico como do ponto de vista filológico, é a segunda, de acordo com os critérios (1")-(2"). Somente sob essa interpretação pode-se compreender como um termo universal (por exemplo, "homem", "lenho", "animal", etc.) pode ser chamado por Aristóteles de "subjacente" 23.

Por essas razões, torna-se claro que é bem justificada a proposta de traduzir de modos distintos a mesma expressão "[legeshai/ kategoreisthai] kath' hypokeimenou", como já temos feito no corpo deste artigo: no contexto das Categorias, essa expressão seria mais bem traduzida como "ser afirmado de um sujeito", ao passo que, no contexto dos Segundos Analíticos e outras obras, essa expressão seria mais bem traduzida por "ser afirmado de algo subjacente", pois a ênfase da expressão consiste no fato de que o sujeito $S$ já está previamente dado e configurado em sua essência, independentemente do predicado heterogêneo que lhe é atribuído. Pelas mesmas razões, convém falar em "sujeito" quando Aristóteles se reporta à noção meramente sintática e/ ou gramatical: aquilo que ocupa a posição de "S" no esquema "S é $P$ " ou em algum esquema equivalente. Mas convém falar em "subjacente" quando Aristóteles se reporta à noção bem mais complexa que está em pauta em Segundos Analíticos 83a 1-14, a qual envolve, de um só golpe, propriedades essenciais referidas a indivíduos, ou indivíduos identificados por propriedades essenciais ${ }^{24}$.

Abstract: This paper examines the notion of subject of predication as it is implied in Aristotle's argument in Posterior Analytics 83a 1-14. I claim that the notion of subject Aristotle develops in that argument is quite different from the notion of subject he advances in Categories, although these notions are far from being incompatible with each other. At the 
end of this paper I also elucidate some reasons for translating "hypokeimenon" accordingly, as "subject" or as "underlying thing".

Keywords: Ontology, Semantics, Predication, Essencialism, Substance, Categories.

\section{NOTAS}

1 O termo grego "hypokeimenon" será aqui traduzido ora por "sujeito", ora por "subjacente", e as justificativas dessas traduções serão dadas na parte final do artigo.

2 A análise da predicação que resultará ao final de minha proposta é compatível com as teses filosóficas centrais defendidas nas Categorias. Minha reserva em relação ao tratado das Categorias diz respeito apenas ao uso das referidas expressões do jargão aristotélico e ao efeito desorientador que a interpretação tradicional teve para a compreensão da ontologia aristotélica. A "anomalia” terminológica das Categorias foi notada por Chen [1958], e Mansion [1946] e [1949]. Mesmo Ackrill [1963], p. 64, admite que os termos técnicos empregados no capítulo 2 das $\mathrm{Ca}$ tegorias "hardly occur as technica terms except in the $\mathrm{Ca}$ tegories".

3 Devo ressaltar que não é claro se a análise da predicação que Aristóteles propõe em Segundos Analíticos I 22 seria adequada também para as sentenças cujo sujeito é um nome próprio. Não é claro o que Aristóteles pensa a respeito desse tipo de sentença, tampouco é claro como ele entende a semântica de um nome próprio. Por isso, deixarei de lado o problema de saber se o que falarei a seguir vale também para as sentenças cujo sujeito é um nome próprio.

4 Mais adiante, ficará claro quais são as razões que Aristóteles supõe para determinar que há uma "ordem correta 
dos termos" e qual ela é. Por enquanto, seja-me permitido supor que há uma ordem correta.

5 Esse uso de "gignetai" é comum na língua grega, mas, para os leitores céticos, convém dar alguns exemplos de sua ocorrência: Ethica Nicomachea 1098a 16, b 20; Motu Animalium 701a 12; Metafísica, 1029a 10.

6 Cumpre sublinhar para o leitor que estou a usar a expressão enfática "é que", que é útil para demarcar uma retificação que se segue à constatação de um erro ("o Brasil não é rico, a China é que é rica").

7 Em princípio, do ponto de vista da lógica, a negação da conjunção entre (i) e (ii) poderia dar-se de tal modo que apenas um dos itens conjuntivos fosse negado. No entanto, como a cláusula (ii), em virtude de seu conteúdo, não pode ser o caso senão quando a cláusula (i) foi admitida como verdadeira, segue-se que os únicos casos possíveis seriam a negação de ambos os itens (i) e (ii) ou a negação de (ii) isoladamente. Essa última alternativa, no entanto, não tem lugar no contexto desse argumento.

8 A opção de considerar a negação apenas com os passos (i) e (ii) não é viável porque, na expressão grega, os passos (ii) e (iii) vêm juntos, compactados no jargão "sumbebeke", de modo que "ouk" não poderia negar (ii) sem negar conjuntamente (iii).

9 As opções já estão simplificadas, no sentido de que as opções claramente inviáveis já estão descartadas, para não entediar o leitor

10 Afinal, apenas repito o que Patzig [1965], p. 12, já havia sugerido. Ver também Williams [1985], que compara a análise aristotélica às descrições definidas de Russell.

11 O principal texto para comparação seria Metafísica 1007a 34- b 13, que examinei com algum detalhe em Angioni 
[2006], p. 72-79.

12 Para os detalhes filológicos da interpretação de "hoper kai egeneto" em 83a 13, remeto a Angioni [2006], p. 122. O pronome relativo "hoper" retoma "hypokeimenon", e "egeneto" tem claramente o sentido de "assumir o papel de", como, de fato, é comum: cf. nota 5. Barnes [1993], p. 116,175 e muitos outros tomam "egeneto" ingenuamente ao pé da letra, como se o termo introduzisse a noção de devir, o que não condiz com o argumento em que Aristóteles está interessado no contexto.

13 Cf. Segundos Analíticos 73b 5-10.

14 Tratei disso com detalhe em Angioni [1998], e voltei ao assunto em Angioni [2006], 114-123.

15 Para detalhes, ver Angioni [2008], p. 142.

16 Cf. Categorias 2a 34- b 6.

17 Cf. 1a 20- b 9: Aristóteles procede a uma classificação quadripartida dos entes, por meio de duas relações: (i) ser afirmado de um sujeito (ii) estar presente em um sujeito (cf. Ackrill [1963], p. 74). Não é estritamente correto dizer que a primeira relação seria estritamente lógica, ao passo que a segunda seria estritamente ontológica. A rigor, Aristóteles não parece conceber que a primeira relação exaure o domínio "lógico", tampouco parece concebê-la por critérios meramente lógicos (cf. nesse sentido, Ackril [1963], p. 75). De todo modo, o que interessa, para meu argumento, é ressaltar que Aristóteles, nas Categorias, não tem como interesse central desenvolver uma teoria da predicação, de modo que é natural que existam diferenças em relação ao que é dito em Segundos Analíti$\cos I 22$.

18 Atenção: não estou a dizer que Aristóteles delimita a noção de sujeito primeiro por critérios apenas gramaticais. 
Não estou a sugerir que Aristóteles justifica a primazia dos indivíduos, como sujeitos primitivos, por critérios meramente gramaticais. A noção de "sujeito primeiro" (que certamente envolve critérios lógico-gramaticais bem como critérios ontológicos) não está no escopo da minha afirmação, nem pretendo ter tratado dela neste artigo. Estou a sugerir que a noção de "sujeito de predicação" é tratada por Aristóteles como se pudesse ser concebida por critérios gramaticais, a partir da mera forma da predicação "S é P".

19 Cf. Segundos analíticos 83a 24-33; 73b 5-10; Física 190a 34- b 1, Metafísica 1017b 10-16. Tratei desses textos em Angioni [1998], p. 97-104, 110-11 e Angioni [2006], p. 124-129.

20 Veja-se o que Aristóteles diz em 2a 29-32. Não preciso discutir como essa tese pode tornar-se compatível com o que Aristóteles afirma 1b 10-15, tampouco preciso discutir como essa tese envolve a noção de homonímia ou paronímia (ver Wedin [2000], p. 17-20, 27), tampouco preciso discutir se há uma distinção, em 2a 19-34, entre predicação lingüística e predicação metafísica (cf. Lewis [1991], p. 54-55, 172-3). Basta-me notar que Aristóteles admite que "o corpo se diz branco", ou seja, o nome "branco" é afirmado do corpo como de um sujeito. Discordo de Ackrill [1963], p. 75, que afirma que essa passagem é mero "slip", no qual Aristóteles está a se expressar sem cuidado. Não há falta de cuidado, por Aristóteles não pretende eliminar a tese de que o termo "branco" ocupa a posição de predicado na sentença "o corpo é branco". Sobre esse ponto, ver Lewis [1991], p. 67-8.

21 Cf. Segundos analíticos 83b 20-24.

22 Esse critério (2') é obtido por negação de (2). A negação 
de uma sentença negativa torna-se uma afirmação: dada a sentença "Sócrates não está sentado", negá-la consiste em algo equivalente a afirmar que "Sócrates está sentado".

23 Não há dúvida de que Aristóteles assim os chama: ver Segundos analíticos 83a 13, Metafísica 1017b 16.

24 Versões preliminares deste artigo foram apresentadas e discutidas em eventos no Rio de Janeiro (UFRJ) e em Goiânia (UFG). Agradeço aos comentários, críticas e sugestões que me foram feitas, em tais ocasiões, por Marco Zingano, Vivianne de Castilho Moreira, André Porto, Araceli Veloso, Raul Landim e Lia Levy. Agradeço ao $\mathrm{CNPq}$ pela Bolsa de Produtividade em Pesquisa, à qual está vinculada a pesquisa que resultou neste artigo.

\section{REFERÊNCIAS}

\section{TEXTOS DE ARISTÓTELES:}

BEKKER, I. Aristotelis opera, vols. I-II. Berlim: Walter de Gruyter, a cura de O. Gigon, 1950.

BODEÜS, R. Aristote - Catégories. Paris: Les Belles Lettres, 2002.

JAEGER, W. Metaphysica. Oxford: Clarendon Press, 1957.

Minio-Paluello, L. Categoriae et Liber De interpretatione. Oxford: Clarendon Press, 1949

Ross. D. Aristotle's Metaphysics - A revised text with introduction and commentary. 2 vols. Oxford: Clarendon Press, 1924.

. Aristotle's prior and posterior analytics. Oxford: Clarendon Press, 1949. 
. Topica et sophistici elenchi. Oxford: Clarendon Press, 1958.

. Aristotle's Physics - a revised text with introduction and commentary. Oxford: Clarendon Press, 1936.

\section{LITERATURA SECUNDÁRIA}

ACKRILL, J. L. Aristotle's Categories and De interpretatione. Oxford: Oxford University Press, 1963.

ANGIONI, Lucas. Não ser dito de um subjacente, 'um isto' e separado: o conceito de essência como subjacente e forma. Cadernos de História e Filosofia da Ciência, série 3, vol. 8, n. especial, p. 69-126, 1998.

- Introdução à teoria aristotélica da predicação. Campinas: Editora da Unicamp, 2006.

. As noções aristotélicas de substância e essência.

Campinas: Editora da Unicamp, 2008.

BARNES, J. Posterior analytics. $2^{\underline{a}}$ ed. Oxford: Oxford University Press. Clarendon Aristotle series,1993.

CHEN, Chung-Hwan. On Aristotle's two Expressions kath' hypokeimenou legesthai and en hypokeimenôi einai. Phronesis 2, p. 148-159, 1957.

LEWIS, Frank A. Substance and predication in Aristotle. Cambridge: Cambridge University Press, 1991.

MANSION, S. La première doctrine de la substance - La substance chez Aristote. In: J. Follon (ed.). Études aristotéliciennes. Louvain-la-Neuve: Institut Supérieur de philosophie, 1984, 1946, p. 283-303. 
. La doctrine aristotélicienne de la substance et le Traité des Categories. In: J. Follon (ed.). Études aristotéliciennes. Louvain-la-Neuve: Institut Supérieur de philosophie, 1984, p. 305-8, 1949.

PATZIG, G.. Aristotle's theory of the syllogism. Trad. J. Barnes, Dordrecht: Heidel, 1965.

WeDIN, Michael. Aristotle's theory of substance: The Categories and Metaphysics Zeta. Oxford, Oxford University Press, 2000.

Williams, C. J. F. Aristotle's theory of descriptions. Philosophical Review 94, no 1, p. 63-80, 1985. 